\title{
DAFTAR ISI
}

\section{Volume 8, Nomor 1, Januari - Juni 2019}

\author{
Halaman (1-8) \\ UJI AKTIVITAS EKSTRAK ETANOL DAUN LIDAH BUAYA (Aloe vera) \\ TERHADAP BAKTERI Staphylococcus aureus DAN JAMUR Candida albicans \\ (Gemy Nastiti Handayani)
}

Halaman (9-20)

UJI KANDUNGAN LOGAM BERAT Pb DAN Hg PADA AIR, SEDIMEN DAN

LAMUN (Enhalus acoroides) DI PERAIRAN TELUK KAYELI

KABUPATEN BURU PROVINSI MALUKU

(Nur Alim Natsir, Debby A. J Selanno, Ch. I. Tupan, Y. T. Male)

Halaman (21-28)

ISOLASI DAN UJI AKTIVITAS BAKTERI PENGHASIL SELULASE ASAL TANAH KANDANG SAPI

(Albert Sembiring)

Halaman (29-41)

PENGARUH PENGGUNAAN MODEL PROJECT BASED LEARNING

TERHADAP KETERAMPILAN KOLABORASI

MAHASISWA PENDIDIKAN IPA

(Sitti Saenab, Sitti Rahma Yunus, Husain)

Halaman (42-46)

PENGARUH LINGKUNGAN BELAJAR DAN KONSEP DIRI TERHADAP

HASIL BELAJAR BIOLOGI SISWA SMP NEGERI I MALUKU TENGAH

(Pebrywati Watimury, Farida Bahalwan)

Halaman (47-58)

LAMA PENYIMPANAN DAGING AYAM BROILER TERHADAP

KUALITASNYA DITINJAU DARI KADAR PROTEIN DAN ANGKA

LEMPENG TOTAL BAKTERI

(Insun Sangadji, Jurianto, Muhammad Rijal)

Halaman (59-70)

PENGARUH KONSENTRASI Saccharomyces cereviceae TERHADAP PRODUKSI BIOETANOL BERBAHAN DASAR BATANG JAGUNG (Muhammad Rijal, Adila Rumbaru, Abajaidun Mahulauw) 
Halaman (71-81)

PENGARUH POLIHERBAL EKSTRAK JERINGAU, TEMU MANGGA DAN BAWANG PUTIH PADA FUNGSI HEPAR TIKUS (Rattus norwegicus)

(Bayyinatul Muchtaromah, Rahmi Annisa, Sofiyah)

Halaman (82-89)

REFUGIA DITINJAU DARI KONSEP GULMA PENGGANGU DAN UPAYA KONSERVASI MUSUH ALAMI

(Asyik Nur Allifah AF, Rosmawati T, Zamrin Jamdin)

Halaman (90-100)

IMPLEMENTASI PENDEKATAN SAINTIFIK PADA SINTAKS

DISCOVERYIINQUIRY LEARNING, BASED LEARNING, PROJECT BASED

LEARNING

(Asmin Banawi) 